\title{
ANALISIS GIMIK KETIDAKADILAN MELALUI PENDIDIKAN BERBASIS LITERASI KRITIS DI SEKOLAH DASAR
}

\author{
Ira Rengganis ${ }^{1}$, Teguh Ibrahim $^{2}$, Winda M. Juwita ${ }^{3}$, Mela Darmayanti ${ }^{4}$ \\ 1,2,4 Universitas Pendidikan Indonesia, ${ }^{3}$ STAI Darul Falah KBB \\ ${ }^{1}$ rengganisira@gmail.com
}

\begin{abstract}
The problem of this research is that there is still a lack of application of critical literacy-based learning processes in elementary schools, especially those that raise criticism of power and injustice. The purpose of this study is to analyze the phenomenon of injustice that often occurs in the community through critical literacy education in elementary schools. The research method used is a case study which is expected to be able to reveal and describe in depth how students can interrogate texts and find sentence structures about injustice. The research subjects were grade 4 students of SDN Sukajadi 07 Bandung. The results showed that with critical literacy education, elementary school students were able to interrogate texts and contest the facts of injustice contained therein. Students are also able to associate these problems with human nature who are greedy, cheating and vile. In addition, students can also produce texts that promote social justice, hopes, important messages and solutions for a better future. This research has significance for strengthening critical pedagogy science in elementary schools
\end{abstract}

Keywords: critical literacy; critical pedagogy; primary school

\begin{abstract}
Abstrak
Masalah dari penelitian ini adalah masih jarangnya penerapan proses pembelajaran berbasis literasi kritis di sekolah dasar, terutama yang mengangkat kritik pada kekuasaan dan ketidakadilan. Tujuan dari penelitian ini adalah melakukan analisis pada fenomena ketidakadilan yang kerap kali terjadi di lingkungan masyarakat melalui pendidikan literasi kritis di sekolah dasar. Metode penelitian yang digunakan adalah studi kasus yang diharapkan mampu mengungkap dan mendeskripsikan secara mendalam bagaimana siswa dapat menginterogasi teks dan menemukan stuktur kalimat tentang ketidakadilan. Subjek penelitian adalah siswa kelas 4 SDN Sukajadi 07 Kota Bandung. Hasil penelitian menunjukkan bahwa dengan pendidikan literasi kritis, siswa sekolah dasar dapat menginterogasi teks dan menggugat fakta ketidakadilan yang ada didalamnya. Siswa juga mampu mengaitkan problematika tersebut dengan sifat manusia yang serakah, curang dan keji. Selain itu siswa juga dapat memproduksi teks yang mempromosikan keadilan sosial, harapan, pesan penting dan upaya solutif untuk masa depan yang lebih baik. Penelitian ini memiliki signifikansi bagi penguatan keilmuan pedagogik kritis di sekolah dasar
\end{abstract}

Kata Kunci: literasi kritis; pedagogik kritis; sekolah dasar

\begin{tabular}{llll}
\hline Received & $: 2020-09-15$ & Approved & $: 2020-12-14$ \\
Reviesed & $: 2020-12-12$ & Published & $: 2021-01-31$ \\
\hline
\end{tabular}

Jurnal Cakrawala Pendas is licensed under a Creative Commons Attribution-

ShareAlike 4.0 International License.

\section{Pendahuluan}

Ketidakadilan sosial adalah sejarah kelam bangsa Indonesia yang seharusnya tidak menjadi warisan sampai detik ini, lama hidup dalam kekangan kolonialisme, rakyat Indonesia telah menahan perih-getirnya penjajahan, penindasan, perampasan hak, penistaan harga diri, kelaparan, kerja paksa, pertumpahan darah, pembunuhan dan yang paling miris adalah rakyat telah kehilangan martabat sebagai manusia merdeka. Itu sebabnya para pahlawan, pejuang kemerdekaan, dan pendiri bangsa mengusung sebuah cita-cita luhur yaitu mewujudkan keadilan sosial bagi seluruh rakyat Indonesia. Tidaklah mudah mewujudkan keadilan sosial 
dikarenakan rongrongan para pengkhianat bangsa ini masih kentara, tengok saja kasus korupsi yang masih marak (Syamsuddin, 2020), Fauzanto, 2020) demokrasi yang tidak sehat (Bland, 2019), interpensi oligarki kekuasaan ((Patittingi and Jurdi, 2016), (Izziyana, 2019)) serta berbagai kebijakan yang tidak pro pada kepentingan rakyat masih menjadi musuh besar keadilan sosial di negara Indonesia hingga saat ini (Muqsith, 2020). Sejumlah penelitian pun menyimpulkan demikian, seperti (Budirahayu, 2020) "pendidikan dihadapkan pada fakta ketidakadilan yang mencakup distributif, prosedural, partisipatif, dan interaksional. Kemudian penelitian (Bidari, 2016) dan (Panjaitan, 2019) menyimpulkan adanya ketidakadilan dari segi perlakuan hukum antara rakyat kecil dengan para wakil rakyat yang terjerat korupsi. Sedangkan temuan Hurairah (2019) menemukan adanya ketimpangan prosedural, ketimpangan sosial dan ketimpangan politik bagi masyarakat miskin dalam aksesibilitas Jaminan Kesehatan Nasional Indonesia.

Melihat ketidakadilan telah merambat dalam berbagai dimensi kehidupan rakyat kecil di Indonesia, maka permasalah ini harus disikapi secara serius. Oleh karena itu perwujudan keadilan sosial harus menjadi utopia setiap insan Indonesia, diwujudkan secara kolaboratif dalam berbagai dimensi kehidupan dengan langkah-langkah strategis, kritis, dan solutif. Tentu saja dunia pendidikan harus menjadi garda terdapan dalam membumikan semangat juang perwujudulan keadilan sosial, bahkan bisa dilakukan sejak dini. Berbicara tentang bagaimana dunia pendidikan membumikan semangat juang keadilan sosial, tentu saja tidak melulu mengajarkan konsep tersebut dengan pendekatan literasi teoritis dan tekstualis. Dalam menghadapi abad 21 dan revolusi industry 4.0, peserta didik harus dapat menggunakan beberapa literatur dan informasi untuk memenuhi tantangan dan mengelola kompleksitas problematika kehidupan sosial, politik, ekonomi, dan teknologi yang ada di luar sekolah ((Silvers, Shorey and Crafton, 2010), (Kress, 2006)). Tentu saja akan lebih menarik jika menghadapkan peserta didik pada beragam fenomena ketidakadilan sosial sebagai negasi dari konsep keadilan sosial. Mungkin sekilas terlihat seperti sebuah paradox, tapi bukankah sejarah yang baik bukan hanya mengingat para pahlawan bangsa, tapi juga mengingat para pengkhianat bangsa (Gerung, 2020) .Dengan mengingat sebuah pengkhianatan, nalar kritis akan bekerja karena dipicu oleh pertanyaan, kekecewaan, kewaspadaan dan terprogram untuk melawan. Bentuk perlawanan yang dimaksud tentu saja bukan anarkisme, tapi dialogisme dan kritisme dalam rangka mencari solusi dan mempromosikan keadilan. Pola pendidikan yang seperti ini sering kali bertautan erat dengan gerakan pendidikan literasi kritis.

Pendidikan literasi kritis nampak tidak terlalu populer, beberapa penelitian menyimpulkan demikian. Bagi banyak pendidik, istilah 'literasi kritis' tidak mudah didefinisikan dan diterapkan di sekolah, salah satu faktor yang menyebabkan literasi kritis sulit untuk diterima adalah karena merangkul perspektif kritis dan sedikit bertentangan dengan kehidupan siswa yang sebagian besar mengikuti arus status quo ((Lie, Fei and Ismail, 2012); (Kaur and Sidhu, 2014)). Artinya praktik literasi kritis melibatkan perspektif yang tidak biasa dari kehidupan siswa, cenderung kritis dan utopis, karena menantang status quo kekuasaan yang tidak memihak pada keadilan. Kemudian literasi kritis juga dianggap sebagai sebuah praktik budaya atau tindakan sosial yang memiliki kekuatan pengubah, sehingga dapat membebaskan masyarakat dari beragam belenggu kekuasaan yang menindas, menantang status quo, menguji berbagai sudut pandang, mempromosikan keadilan dan melahirkan gagasan utopis tentang tatanan kehidupan masyarakat yang lebih baik dan demokratis, paradigm ini disebut dengan literasi kritis (Freire and Macedo, 2005), Lewison et al. 2002, (Cooper, K., \& White, no date), (Lee, 2016), Anderson 2019). 
Berkaitan dengan hal tersebut, selama dua tahun kebelakang, peneliti melakukan studi pembedahan teks pada buku ajar kurikulum 2013 yang menyimpulkan bahwa teks berbasis literasi kritis masih jarang ditemukan pada buku ajar tematik kurikulum 2013 (Hendriani, Nuryani and Ibrahim, 2018) . Misalnya, hasil analisis pada tema tentang pekerjaan, teks bacaan yang disuguhkan hanya seputar pekerjaan yang umum diketahui. Seperti gambar di bawah ini :

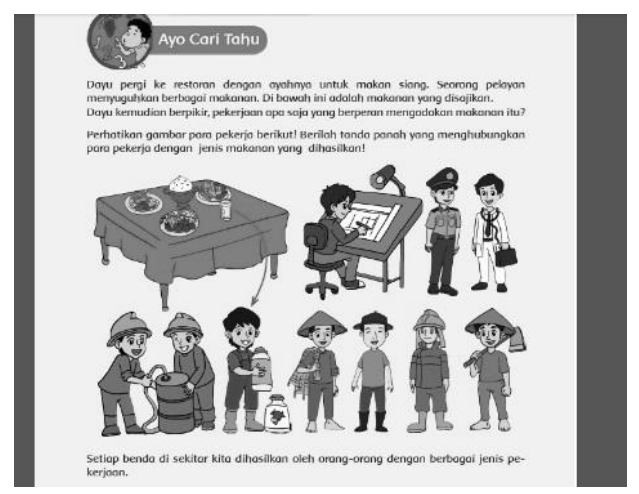

Gambar 1. Teks Tentang Pekerjaan Buku Tematik Kelas IV Tema: Cita-Citaku

Mengacu pada gambar tersebut, instruksi yang diberikan kepada siswa adalah mengidentifikasi beragam pekerjaan yang ada pada sebuah restoran, kemudian menganalisis keterkaitan fungsi dari pekerjaan tersebut dengan aktivitas yang ada di restoran. Padahal jika pahami secara kritis, sejatinya banyak sekali fakta ketidakadilan sosial yang berkaitan dengan tema pekerjaan. Contohnya eksploitasi anak untuk menjadi pekerja oleh pihak-pihak yang tidak bertanggung, isu pengangguran, isu pemberhentian hubungan kerja atau fenomena pelamar ojek online yang terus terjadi secara massif. Fakta-fakta tersebut seharusnya bisa menjadi tema-tema ketidakadilan yang bisa digugat oleh peserta didik dalam suatu dialog kelas. Contoh selanjutnya, analisis pada tema keseimbangan ekosistem, penulis tidak menemukan fenomena problematis yang dibahas. Pembahasan hanya berkisar pada rantai makanan dan jenis-jenis ekosistem. Padahal banyak sekali kasus eksploitasi alam yang jarang diungkap pada lingkungan sekolah dasar. Seperti kasus pemburuan hiu untuk diambil siripnya, atau eksploitasi sumber daya alam air secara berlebihan oleh pihak swasta. (Rengganis $d k k ., 2019$ )

Mengacu pada beberapa hasil penelitian tersebut, maka terdapat kesenjangan antara fakta dan kondisi ideal yang seharusnya terjadi. Pembelajaran tematik dengan sentuhan literasi kritis masih kurang familiar bagi para pendidik dan siswa sekolah dasar khususnya di Indonesia. Oleh sebab itu, penelitian ini berusaha mengisi kekosongan tersebut dengan menyajikan deskripsi kualitatif proses pendidikan literasi kritis yang dilakukan selama dua tahun terakhir di beberapa Sekolah Dasar kota Bandung dalam rangka mempromosikan dan memperjuangkan keadilan sosial bagi seluruh rakyat Indonesia dengan cara menginterogasi teks-teks yang merepesentasikan beragam fenomena ketidakadilan sosial, kemudian secara kritis melakukan rekonstruksi teks secara argumentatif dan dialogis dalam rangka menggugatnya.

\section{Metode Penelitian}

Penelitian ini menggunakan paradigma kualitatif dengan menggunakan pengaturan alamiah yang bertujuan mengungkap fenomena yang terjadi dengan melibatkan peneliti sebagai instrument utama. Penelitian kualitatif memfokuskan diri pada usaha memahami dan memaknai situasi alamiah yang terjadi berdasarkan narasi verbal dan observasi dibandingkan dengan menggunakan angka-angka dalam mendeskripsikan sebuah fenomena. Adapun 
metode penelitian kualitatif yang digunakan adalah studi kasus, metode ini berusaha menganalisis praktek pembelajarna literasi kritis di sekolah dasar yang terfokus pada upaya guru dan siswa melakukan problematisasi terhadap fakta ketidakadilan dan kekuasaan yang tidak memihak. Studi kasus adalah penelitian empiris yang dirancang untuk mengumpulkan dan menganalisis data dari beberapa kasus kehidupan nyata dan memberikan pemahaman mendalam tentang isu-isu spesifik (Cresswell, 2019). Studi kasus memungkinkan peneliti "untuk membangun koneksi secara teoritis antara peristiwa dan fenomena yang sedang diteliti" (Mitchell, 1988). Metode studi kasus juga menyoroti upaya penulis sebagai gurupeneliti dalam merefleksikan praktek pembelajaran berbasis literasi kritis yang telah membantu siswa dalam mengembangkan kemampuan analitik-kritis terhadap isu-isu yang berkaitan denga kekuasaan dan ketidakadilan. Selain itu, studi kasus ini juga menganalisis artefak atau karya literasi kritis yang dirancang oleh siswa selama proses interogasi dan dekonstruksi teks.

Subjek penelitian ini adalah siswa sekolah dasar kelas 4 SDN Sukajadi 07 Kota Bandung, Jawa Barat tahun ajaran 2018-2019. Peneliti dan guru sekolah tersebut berkolaborasi melakukan lesson study dengan pendekatan praksis pendidikan yang memiliki pola (refleksi-aksi-transformasi). Guru dan peneliti merumuskan proses pembelajaran tematik dengan pendekatan literasi kritis mulai dari perencanaan, pelaksanaan, observasi, evaluasi dan perbaikan lebih lanjut. Penelitian ini juga menempatkan peneliti sebagai instrument utama dalam mengamati beragam temuan penting penelitian, peneliti merefleksikan pengalamannya dalam mengimplementasikan praktik pendidikan literasi kritis selama kurang lebih dua tahun, sehingga artefak yang ada pada penelitian ini didadapatkan dalam kurun waktu yang berbeda pula.

\section{Analisis Data}

1. Peneliti mengadopsi kerangka teori The New London Group (Cazden et al., 1996) dan (Kress, 2006) untuk analisis data. Mereka berteori bahwa pembelajarn literasi harus membantu siswa untuk (a) memanfaatkan sumber daya multimodal yang dimiliki untuk mempertanyakan pesan teks dan mendesain ulang teks untuk menghasilkan makna alternatif dan (b) memanfaatkan nilai-nilai budaya dan epistemologis yang dikenal untuk menafsirkan dunia.

2. Untuk hasil penerapan proses pendidikan literasi kritis peneliti menggunakan triangulasi analisis data melalui catatan reflektif dari diri peneliti sebagai dosen sekaligus praktikan guru, catatan lapangan dari observer yang didiskusikan secara partisipatif melalui FGD dengan guru kelas. Hasilnya dideskripsikan secara kronologis berdasarkan sintaks atau tahapan pembelajaran.

3. Aspek visual dan dan tekstual dari karya literasi kritis siswa ditranskripsikan menggunakan kerangka kerja metodologis untuk analisis interaksional multimodal, sebuah metode analitik yang berkaitan dengan menggambarkan apa yang orang ungkapkan dan bereaksi terhadap dalam situasi interaksi spesifik (Norris, 2018).

4. Untuk analisis artefak siswa (gambar ilustrasi dan karangan argumentasi siswa), peneliti menggunakan pendekatan semiotik sosial multimodal, sebuah metode analitik yang berfokus pada pemahaman bagaimana individu menggunakan semua mode representasi sebagai sumber daya sosial yang bermakna (Bezemer, J., \& Jewitt, 2016). Gambar ilustrasi dan reproduksi teks argumentasi dikategorikan secara tematis sesuai dengan pertanyaan penelitian dan untuk menghasilkan kriteria untuk pengambilan sampel data. peneliti fokus 
pada interpretasi kritis tentang bagaimana siswa menggunakan gambar dan bahasa untuk memproblematisasi ketidakadilan dan relasinya dengan kekuasaan yang tidak memihak pada kepentingan rakyat.

\section{Hasil dan Pembahasan}

Pendidikan Literasi Kritis dengan Tema Kepala Desa yang Serakah

Proyek pertama ini dilaksanakan pada bulan September 2018 di SDN Sarijadi 07 Kota Bandung dengan subjek penelitian siswa kelas empat sekolah dasar. Setelah melakukan analisis kurikulum dan payung tema, maka momentum pelaksanaan penelitian bertepatan dengan tema makanan bergizi, sub tema buah-buahan segar. Berdasarkan pengamatan penulis, tema buah-buahan bergizi tidak mengangkat isu atau problematika yang dapat disikapi secara kritis oleh peserta didik. Sehingga peneliti berdiskusi dengan guru dan mencari alternatif tentang bagaimana membumbui tema buah-buahan dengan balutan literasi kritis. Hasil dari diskusi maka muncullah sebuah ide untuk mengangkat tema komodifikasi buahbuahan langka yang dilakukan oleh seorang kepala desa yang serakah. Cerita pendek berbentuk fiksi, semua tokoh dan kejadian hanyalah karangan penulis naskah. Meskipun berbentuk fiksi, akan tetapi naskah tersebut merupakan representasi dari kehidupan nyata karena tidak dapat dipungkiri ada beberapa kasus kepala desa yang berbuat tidak adil kepada rakyatnya.

Pada penelitian ini, tema buah-buahan bergizi difokuskan pada buah yang sudah dinilai langka dan sulit didapatkan seperti buah Ciplukan yang memiliki banyak manfaat menurunkan kadar gula dalam darah. Menurut (Sa'diyah, 2018) buah ciplukan mengandung senyawa alkaloid, flavonoid, dan saponin. Alkaloid berperan sebagai pelindung tumbuhan dari serangan hama dan memberikan rasa pahit pada jaringan tumbuhan seperti memberikan rasa pahit pada daun. Kandungan alkaloid dapat bekerja sebagai antipiretik, antiinflamasi, antibakteri dan antihiperglikemia (anti-diabeters). Buah ciplukan mulai jarang ditemui dan termasuk tanaman langka, sehingga keberadaanya cukup sulit ditemukan. Mengacu pada gagasan tersebut, tujuan mengangkat tema buah-buahan langka yang dikomodifikasi oleh kepala desa yang berkuasa diharapkan dapat memfasilitasi peserta didik berpikir kritis dalam mengungkap kedok kepemimpinan yang tidak adil serta mempromosikan keadilan pada tahapan berikutnya. Senada dengan pendapat Comber yang mengemukakan bahwa "literasi kritis menandai penggunaan bahasa sebagai alat untuk meningkatkan kualitas kehidupan, dan / atau mempertanyakan sumber keistimewaan dan ketidakadilan (Comber, 2001). Keasyikan utama pendidikan literasi kritis adalah dengan ketidakadilan sosial dan bagaimana mengubah lembaga yang tidak adil dan menindas menjadi lebih demokratis (Burbules, N. C. \& Berk, 2008). Selain itu penelitian (Tarhan, 2018) juga menyimpulkan bahwa dalam proses pembelajaran siswa perlu memiliki pemahaman mendalam tentang konsep keadilan dan ketidakadilan, serta bagaimana mereka mengalaminya dalam kehidupan sehari, bagaimana perasaan mereka dan bagaimana mereka berperilaku ketika mereka menghadapi ketidakadilan.

Pada tahap awal pembelajaran guru bertanya jawab tentang buah-buah langka yang mendekati kepunahan, buah langka ini memiliki banyak khasiat seperti mengobati berbagai penyakit kulit dan juga meringan diabetes. Guru juga dapat menyajikan video yang berhubungan dengan tanaman dan buah langka di Indonesia. Kemudian pada tahap problematisasi guru menyampaikan sebuah cerita tentang fenomena buah langka yang dikomodifikasi secara tidak adil oleh seroang kepala desa. Cerita diwarnai dengan kelakuan kepala desa yang angkuh, serakah, dan anti-kritik. Adapun perbuatan tidak adil yang dilakukan kepala desa diantaranya memungut pajak yang besar, memonopoli perdagangan 
buah langka, dan juga membakar kebun buah ciplukan milik warga. Setelah siswa selesai mendengarkan cerita, guru membangun dialog dengan melakukan curah pendapat mengenai watak tokoh dalam cerita, alur cerita, serta pengalaman siswa yang berkaitan dengan cerita. Guru membantu siswa menandai (kodifikasi) dan mengurai (dekodifikasi) fakta tersembunyi yang ada dalam cerita dan keterkaitannya dengan masalah yang mereka alami dalam kehidupan sehari-hari. Pada tahap ini peneliti memberikan LKP Pra-membaca yang berfungsi menggali skemata siswa pada watak tokoh yang ada dalam cerita. Adapun LKP Pra-membaca dapat dilihat pada gambar 2 di bawah ini :
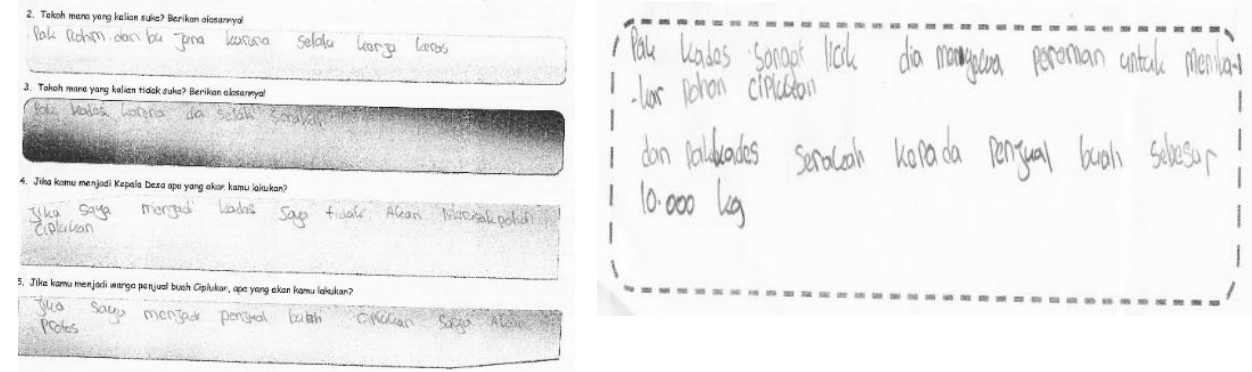

Gambar 2. Lembar Kerja Pra-Baca

Mengacu pada LK pra-baca tersebut, terlihat jawaban siswa sudah mampu mengidentifikasi watak tokoh yang ada pada cerita dan mencari informasi tentang peristiwa sosial yang ada pada teks dengan kata kunci kelicikan, keserakahan dan ketidakadilan. Melalui aktivitas membaca kritis siswa dapat menemukan relasi antara kekuasaan dengan kelicikan yang sejatinya mencerminkan ketidakadilan. Selaras dengan temuan Forest bahwa penelitiannya menunjukkan bahwa siswa mampu menerapkan literasi kritis dengan cara (1) menganalisis identitas sosial dan norma-norma yang jelas dalam teks; (2) menanggapi watak tokoh dan peristiwa dari berbagai sudut pandang; (3) menginterogasikan masalah kekuasaan, otoritas, dan agensi; serta (4) menganalisis sejarah dan budaya. (Forest and Kimmel, 2016). Setelah siswa menemukan fakta tersembunyi tentang ketidakadilan penguasa, maka langkah selanjutnya dari pembelajaran tematik berbasis literasi kritis adalah memproduksi karya literasi sebagai bentuk kritik, agensi, harapan dan ajuan solusi. Literasi kritis menyediakan struktur untuk memahami bagaimana pembaca menghubungkan, berinteraksi, dan terlibat dengan teks untuk membangun (kembali) makna baru dan mengembangkan representasi mental dari teks (Palincsar and Schutz, 2011). Untuk mengembangkan representasi mental dari teks dibutuhkan aktivitas berpikir kritis, oleh karenanya pada tahap ini peserta didik dikondisikan untuk melaksanakan kegiatan menulis karangan argumentasi kritis. 
Tabel 1. Contoh Karya Literasi Kritis Siswa pada Tema Kepala Desa yang Serakah

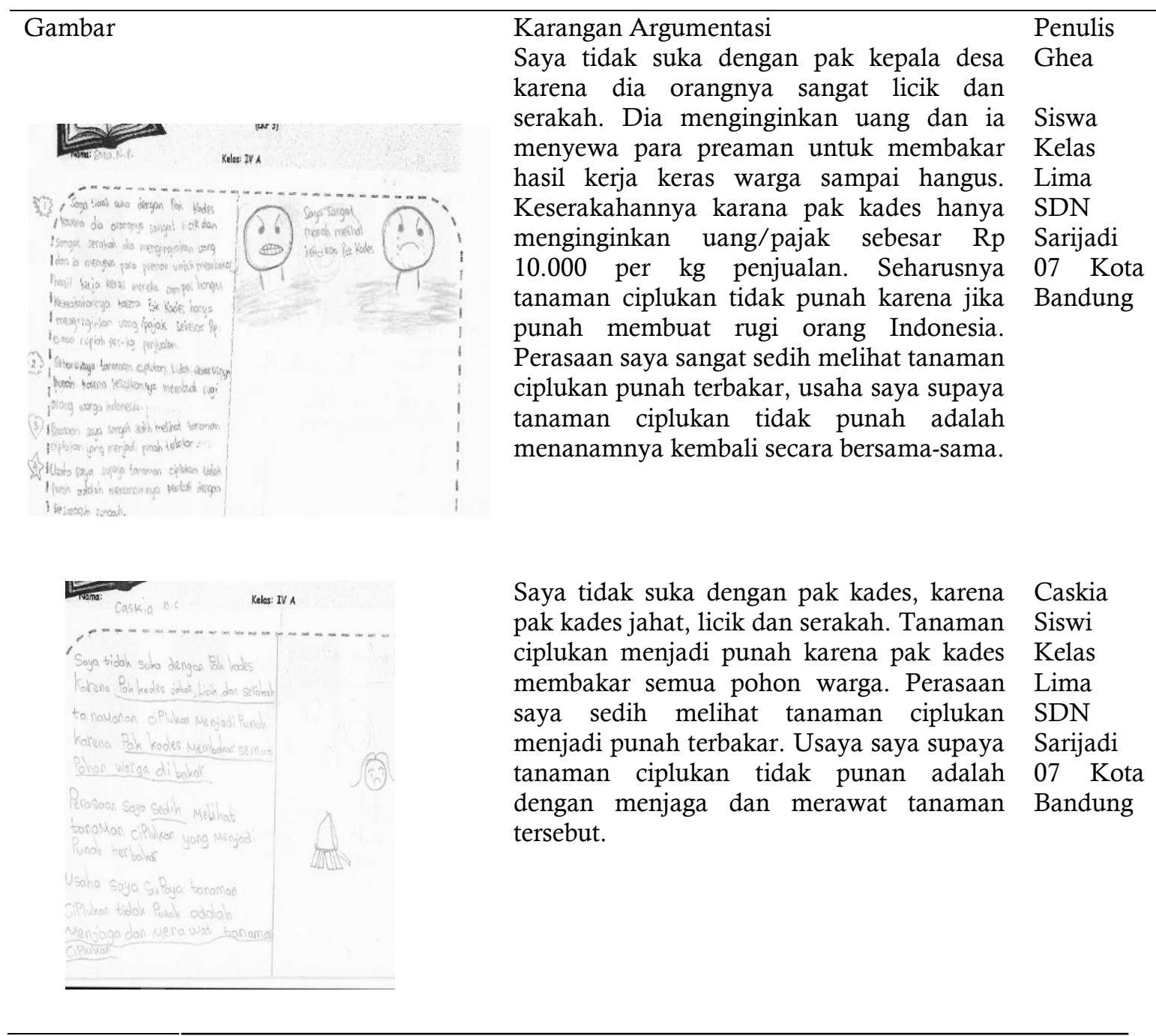

Mengacu pada tabel 1. tersebut, maka dapat dipahami bahwa aktivitas menulis karangan argumentasi kritis siswa dapat memberikan perspektif lain pada fakta-fakta sosial tentang ketidakadilan, ada kalimat yang merepresentasikan kejengkelan dan kebencian pada watak kepala desa yang jahat, licik dan serakah. Selain itu juga siswa mampu merumuskan harapan dan solusi kedepannya agar pohon ciplukan tetap dapat dilestarikan. Selaras dengan penelitian yang dilakukan oleh (Yanda, 2018) bahwa teks dengan pendekatan literasi kritis dapat dijadikan bahan renungan untuk menggali nilai-nilai kehidupan, kemudian dalam penelitian Siregar (2018) yang menyimpulkan bahwa pembelajaran berbasis literasi kritis dapat mengasah kecerdasan moral. Sifat sinistik terhadap keserakahan dan kepicikan adalah bagian dari kecerdasan moral, karena ada pertentangan batin dengan nilai-nilai kebajikan dalam kehidupan sosial, terutama nilai keadilan sosial yang menjadi bagian dari sila kelima Pancasila. Kecerdasan moral juga berkaitan tentang bagaimana keterampilan berpikir untuk mengeksplorasi nilai etika (baik-buruk) yang ada pada teks serta negasinya yaitu pelanggaran etika. Perilaku serakah dan licik adalah perilaku amoral dan tentunya termasuk pada pelanggaran etik sebagai seorang pemimpin

Pembelajaran Literasi Kritis dengan Tema Kecurangan Pedagang

Proyek pertama ini dilaksanakan pada bulan Oktober 2019 di SDN Sarijadi 07 Kota Bandung dengan subjek penelitian siswa kelas empat sekolah dasar. Setelah melakukan analisis kurikulum dan payung tema, maka momentum pelaksanaan penelitian bertepatan 
dengan tema makanan bergizi, sub tema jajanan sehat. Berdasarkan pengamatan penulis, tema jajahan sehat tidak mengangkat isu atau problematika yang dapat disikapi secara kritis oleh peserta didik. Sehingga peneliti berdiskusi dengan guru dan mencari alternatif tentang bagaimana membumbui tema jajahan sehat dengan balutan literasi kritis. Hasil dari diskusi maka muncullah sebuah ide untuk mengangkat tema pedagang jajanan sekolah yang curang.

Pada tema ini, tahap problematisasi dilaksanakan dengan menyajikan sebuah cerita yang merepresentasikan isu kecurangan para pedagang jajanan di sekolah yang menggunakan bahan makanan yang kadaluarsa, tidak steril, dan tidak memenuhi standar kesehatan. Dan ini adalah perbuatan curang karena hanya demi meraup keuntungan dan mengabaikan kesehatan konsumen. Problematika ini sering terjadi di Indonesia, contohnya penggunaan borax pada jajanan baso, saus kadaluarsa, penggunaan air mentah pada minuman dan banyak lagi. Seperti temuan penelitan yang dilakukan oleh (Paratmanitya and Veriani, 2016) yang menyimpulkan bahwa: "Terdapat 107 sampel makanan dari 68 SD yang diuji. Jenis makanan jajanan yang diduga mengandung bahan kimia berbahaya yang paling banyak dijajakan di SD adalah jenis bakso (bakso, bakso tusuk, bakso goreng) yaitu sejumlah $22,4 \%$ dari seluruh sampel jajanan. Di antara 98 sampel yang diuji kandungan boraks dan formalinnya, 15 sampel $(15,3 \%)$ positif mengandung boraks dan 25 sampel $(25,5 \%)$ positif mengandung formalin. Di antara 15 sampel yang diuji kandungan rhodamin-B-nya, 7 sampel (46,7\%) positif mengandung rhodamin-B. Temuan penelitian tersebut tentu saja bukan kabar baik, guru dan orangtua harus senantiasa memberikan arahan kepada siswa sekolah dasar agar lebih selektif dalam memilih jajanan. Problematika ini dirasa cocok dijadikan suplemen pembelajaran tematik dengan sub-tema jajanan sehat.

Pada tahap ini guru bercerita tentang dua pedagang jajanan yang memiliki watak berbeda. Pedagang pertama bernama Mang Ayi, ia memiliki sifat yang baik hati, jujur, disiplin dan memiliki motivasi untuk mengharumkan nama Indonesia dengan jajanan khasnya. Pedagang kedua bernama mang Kasim yang memiliki perangai kurang baik serta berniat mencari keuntungan dengan berbagai cara. Mang kasim mencampurkan bahan-bahan murah dan kurang berkualitas dalam jajanan makanan yang ia buat sehingga menyebabkan beberapa siswa mengalami sakit perut dan muntah. Cerita pendek berbentuk fiksi, semua tokoh dan kejadian hanyalah karangan penulis naskah.

Pada tahap ini guru membangun dialog dengan melakukan curah pendapat mengenai watak tokoh dalam cerita, alur cerita, serta pengalaman siswa yang berkaitan dengan cerita. Guru membantu siswa menandai (kodifikasi) dan mengurai (dekodifikasi) fakta tersembunyi yang ada dalam cerita dan keterkaitannya dengan masalah yang mereka alami dalam kehidupan sehari-hari. Tahap selanjutnya peneliti mengkondisikan siswa ke dalam beberapa kelompok membaca kritis dan intensif dalam rangka menginterogasi teks. Dalam kegiatan ini, siswa tidak hanya ditugaskan mencari informasi penting, mereka juga ditugaskan untuk melakukan analisis wacana kritis dan menemukan kalimat yang merepresentasikan masalah, tahap ini dibantu oleh kata kunci, sebagai contohnya kata "licik atau curang", siswa harus mencari peristiwa sosial yang berhubungan dengan kata tersebut.

Langkah ini bertujuan untuk mengembangkan kemampuan membaca kritis siswa sekolah dasar. Melalui kegiatan pencarian informasi dengan kata kunci "licik" atau "curang" dalam teks diyakini membantu mengasah mata analitik mereka terhadap realitas sosial yang terjadi pada teks. Berkaitan dengan hal ini, literasi kritis menunjukkan keterlibatan mengenai partisipasi dinamis dengan informasi di sekitar kita yang memerlukan kebutuhan untuk 
berpikir kritis (Pescatore, 2007) . Terlebih lagi, literasi kritis juga dapat didefinisikan sebagai pengetahuan untuk mendekati informasi secara kritis dan metodis dengan menilai pengetahuan yang ada (Hammond and Macken-Horarik, 1999). Literasi kritis juga merupakan bentuk pemahaman lanjutan yang melibatkan evaluasi kritis untuk memahami informasi dari teks. Penggambaran ini selanjutnya dianjurkan oleh (Hammond and Macken-Horarik, 1999) yang menyatakan bahwa dasar-dasar literasi kritis berkisar pada keterampilan membaca dan menulis dengan mata kritis lebih banyak lagi dalam beragam dimensi kehidupan.

Setelah siswa mampu menemukan fakta tersembunyi dalam cerita tersebut, tahapan selanjutnya guru meminta siswa merancang alat pendeteksi racun dalam makanan dengan disertai karangan argumentasi yang merepresentasikan alasan, manfaat dan pesan yang disampaikan dari pembuatan alat tersebut. Tahapan ini dalam pendidikan literasi kritis disebut dengan tindakan sosial (social action), bisa berhasil jika tahap sebelumnya berjalan dengan dialektis. Diawaili dengan refleksi kritis terhadap masalah kecurangan pedagang, membangun kepekaan terhadap penyebab dan dampak jangka panjang jika kecurangan tersebut terus terjadi, dan kemudian membangun semangat untuk menghentikan geliat kecurangan. Berkaitan dengan hal ini Koh menyatakan bahwa : literasi kritis adalah tentang bagaimana cara memposisikan penulis sebagai agensi dengan agenda menggunakan bahasa untuk menggambarkan realitas. Hal ini tentunya melampaui nilai nominal teks dan lebih kepada mempertanyakan representasi realitas dalam teks ((Koh, 2002)). Selanjutnya (Fairclough, 2014) menganjurkan agar siswa diberi kesempatan untuk berlatih menulis dalam posisi yang berbeda dan dipandu untuk mewujudkan dampak sosial dari pilihan bahasa yang mereka tujukan pada orang lain. Mereka juga harus bertanggung jawab atas risiko yang mereka ambil ketika mereka menentang ketimpangan sosial yang terjadi. Berikut penulis sajikan beberap hasil karangan argumentasi yang dihasilkan siswa sekolah dasar.

Tabel 2. Karya Literasi Kritis Siswa pada Tema Pedagang Jajanan yang Curang

Gambar
Karangan Argumentasi




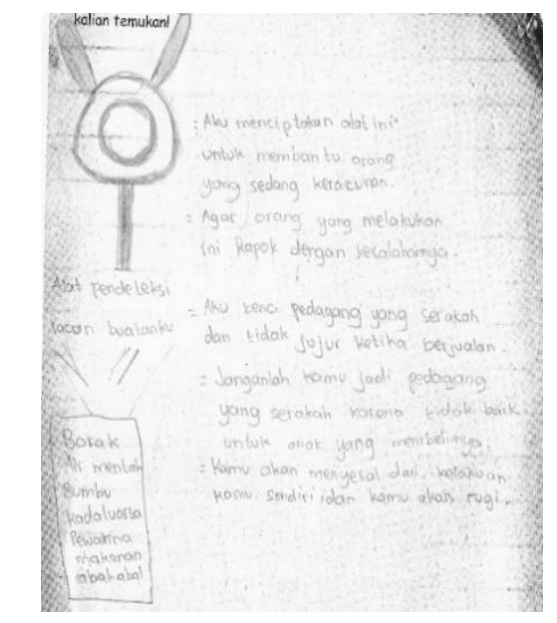

"aku menciptakan alat pendeteksi racun

Ghea ini untuk membantu orang yang sedang Siswi keracunan. Agar orang yang melakukan ini (meracuni makanan) kapok. Aku benci pedagang yang serakah dan tidak jujur ketika berjualan. Janganlah kamu menjadi pedagang yang serakah karena tidak baik untuk anak yang membelinya. Kamu akan menyesal dengan kelakukan Kelas Lima SDN Sarijadi 07 Kota Bandung kamu sendiri, kamu akan rugi"

Karya literasi kritis pada tabel 2 tersebut merepresentasikan luapan kritik, sedikit kebencian, harapan, dan pesan penting. Pada karya literasi kritis tersebut siswa mampu berpikir kritis dengan menyadari adanya masalah dan dampak negatif dari kecurangan, siswa juga mampu berperan sebagai agensi dengan menciptkan alat pendeteksi racun, siswa mampu mengemukakan alasan normatif dari keinginannya membuat alat tersebut. Selaras dengan pendapat (Cooper, K., \& White, 2008) yang mengemukakan bahwa "Literasi Kritis merupakan kapasitas untuk membaca kata dan dunia, menghubungkan pengembangan efikasi diri, sebuah sikap pencarian, dan keinginan untuk mempengaruhi perubahan sosial yang positif". Mengacu pada pendapat Cooper, penekanan pada pendidikan literasi kritis tentunya adanya kesadaran utopis, yaitu keinginan akan suatu perubahan yang positif. Diperkuat oleh (Simon, 1992) yang menyatakan bahwa : Critical literacy has to take seriously the ways in which meaning systems are implicated in reproducing domination and it has to provide access to dominant languages, literacies and genres while simultaneously using diversity as a productive resource for redesigning social futures and for changing the horizon of possibility (Simon, 1992). Mengacu pada pendapat Simon, dapat dipahami bahwa pendidikan literasi kritis membuka harapan akan masa depan yang lebih baik. Terutama dalam memperbaiki sistem yang mendominasi sehingga membatasi ruang gerak manusia untuk mengemansipasi kehidupan. Pendidikan literasi kritis membangkitkan kesadaran sosial peserta didik untuk berperan sebagai agensi yang mampu membawa perubahan-perubahan positif bagi realitas sosial di masa depan.

\section{Kesimpulan}

Penelitian ini telah membuktikan bahwa pendidikan literasi kritis adalah sebuah keniscayaan yang dapat dipraktekan pada ruang kelas jenjang sekolah dasar. Melalui pendidikan literasi kritis siswa sekolah dasar akan dihadapkan pada fakta tersembunyi yang menjadi penyebab munculnya ketidakadilan dalam kehidupan sosial manusia. Melalui dialog kritis, analisis wacana kritis, dan menulis argumentasi kritis siswa sekolah dasar dapat mendeskripsikan profil masalah dengan beragam representasi, mereka juga mampu menganalisis gimik dan kausalitas antara ketidakadilan dengan sikap manusia yang serakah, keji, dan matrealistik. Selain itu, siswa sekolah dasar juga mampu untuk memproduksi teks dan gambar berbasis literasi kritis dalam perspektif yang berbeda dengan mengangkat kritik, saran, harapan, utopia dan alternatif solusi di masa depan. Penelitian ini memiliki signifikansi bagi perkembangan keilmuan pedagogik kritis dan pedagogik mulitiliterasi di sekolah dasar. 


\section{Daftar Pustaka}

Anderson, A. (2019) 'Advancing Global Citizenship Education Through Global Competence and Critical Literacy: Innovative Practices for Inclusive Childhood Education', SAGE Open, 9(1). doi: 10.1177/2158244019826000.

Bezemer, J., \& Jewitt, C. (2016) BOOK CHAPTER Multimodal Analysis: Key Issues.

Bidari, A. (2016) 'KETIDAKADILAN HUKUM BAGI KAUM SANDAL JEPIT', 4(1), pp. 64-75.

Bland, B. (2019) 'Politics in Indonesia: Resilient elections, defective democracy', (April), p. 23. Available at: https://www.lowyinstitute.org/sites/default/files/Bland_Politics in Indonesia_WEB_0.pdf.

Budirahayu, T. (2020) 'Volume II', Caroline of Lichtfield, II, pp. 79-158. doi: $10.4324 / 9781315649412-3$.

Burbules, N. C. \& Berk, R. (2008) 'Critical Literacy for school improvement: An action research project', Improving Schools, 11(2), pp. 101-113. doi: $10.1177 / 1365480208091103$.

Cazden, C. et al. (1996) 'The New London Group', A Pedagogy of Multiliteracies, pp. 60-93.

Comber, B. (2001) 'Critical literacy: Power and pleasure with language in the early years', 5.

Cooper, K., \& White, R. E. (2008) 'Critical Literacy for school improvement: an action research project. Improving Schools', 11(2), pp. 101-113. Available at: d.

Cresswell (2019) 'Ketidakadilan Bagi Masyarakat Miskin dalam Aksesibilitas Jaminan Kesehatan Nasional Di Kota Bandung', Jispo, 9(1), pp. 455-469.

Fairclough, N. (2014) Critical language awareness. Routledge.

Fauzanto, A. (2020) 'Pertanggungjawaban Keuangan Desa Berdasarkan Prinsip', Widya Yuridika: Jurnal Hukum, 3(1), pp. 43-52.

Forest, D. and Kimmel, S. (2016) 'Critical Literacy Performances in Online Literature Discussions', Journal of Education for Library and Information Science Online, 57(4), pp. 283-294. doi: 10.12783/issn.2328-2967/57/4/3.

Freire, P. and Macedo, D. (2005) Reading the Word and the World. London: Routledge. doi: https://doi.org/10.4324/9780203986103.

Gerung, R. (2020) 'Long Time No See! Rocky Gerung: yang Terbakar Bukan Kejagung, tapi Pasar Gelap Keadilan!', ILC tvOne. Available at: https://www.youtube.com/watch? $\mathrm{v}=1 \mathrm{xO}-\mathrm{v} 5 \mathrm{SDB} 1 \mathrm{Y} \& \mathrm{t}=165 \mathrm{~s}$.

Hammond, J. and Macken-Horarik, M. (1999) 'Critical literacy: Challenges and questions for ESL Classrooms. "TESOL Quarterly,33”, pp. 528-543.

Hendriani, A., Nuryani, P. and Ibrahim, T. (2018) 'Pedagogik Literasi Kritis ; Sejarah, Filsafat Dan Perkembangannya Di Dunia Pendidikan', Pedagogia, 16(1), p. 44. doi: 10.17509/pdgia.v16i1.10811.

Izziyana (2019) 'Korupsi Dalam Dimensi Kekuasaan', 1(2).

Kaur, S. and Sidhu, G. K. (2014) 'Evaluating the Critical Literacy Practices of Tertiary Students', Procedia - Social and Behavioral Sciences, 123, pp. 44-52. doi: 10.1016/j.sbspro.2014.01.1396.

Koh, A. (2002) 'Towards a critical pedagogy: Creating "thinking schools" in Singapore', Curriculum Studies, 34. doi: 10.1080/00220270110092608.

Kress, G. (2006) Literacy in the New Media Age (review), Language. doi: 10.1353/lan.2006.0242.

Lee, C. (2016) '(literacy)Teaching Multiple Literacies and Critical Literacy to Pre-', 12(1).

Lie, K. Y., Fei, W. F. and Ismail, K. (2012) 'Students' critical consciousness through critical literacy awareness', GEMA Online Journal of Language Studies, 12(2), pp. 727-743.

Muqsith, M. A. (2020) 'UU Omnibus Law yang Kontroversial mengesahkan Omnibus Law RUU Cipta Kerja ( Ciptaker ) pada Rapat', 'Adalah, 4(12), pp. 109-115. Available at: http://103.229.202.71/index.php/adalah/article/view/17926.

Norris, S. (2018) Analyzing multimodal interaction: A multimodal framework, e-conversion - Proposal for a Cluster of Excellence. London: Routledge.

Palincsar, A. S. and Schutz, K. M. (2011) 'Reconnecting strategy instruction with its 
theoretical roots', Theory into Practice, 50(2), pp. 85-92. doi: 10.1080/00405841.2011.558432.

Panjaitan, B. (2019) 'Melawan Ketidakadilan.', JURNAL PIONIR, 5(3).

Paratmanitya, Y. and Veriani, A. (2016) 'Kandungan bahan tambahan pangan berbahaya pada makanan jajanan anak sekolah dasar di Kabupaten Bantul', Jurnal Gizi dan Dietetik Indonesia (Indonesian Journal of Nutrition and Dietetics), 4(1), p. 49. doi: 10.21927/ijnd.2016.4(1).49-55.

Patittingi, F. and Jurdi, F. (2016) Korupsi kekuasaan: dilema penegakan hukum di atas hegemoni oligarki. PT. RajaGrafindo Persada.

Pescatore, C. (2007) 'Current Events as Empowering Literacy: For English and Social Studies Teachers', Journal of Adolescent \& Adult Literacy - J ADOLESC ADULT LITERACY, 51, pp. 326-339. doi: 10.1598/JAAL.51.4.4.

Rengganis, I. et al. (2019) 'Pendekatan Literasi Kritis Di Sekolah Dasar', 11(1), pp. 75-85.

Sa'diyah, F. (2018) 'MUTU FISIK SEDIAAN SUSPENSI EKSTRAK ETANOL BUAH CIPLUKAN ( Physalis angulata linn .) PHYSICAL QUALITY TEST FOR SUSPENSION PREPARATION OF CIPLUKAN FRUIT ETANOL EXTRACT (( Physalis angulata linn .) Farida Aminatus Sa, diyah Akademi Farmasi Putra Indonesia', pp. 1-9.

Silvers, P., Shorey, M. and Crafton, L. (2010) 'Critical literacy in a primary multiliteracies classroom: The hurricane group', Journal of Early Childhood Literacy, 10(4), pp. 379-409. doi: $10.1177 / 1468798410382354$.

Simon, R. I. (1992) Teaching against the grain: Texts for a pedagogy of possibility. Greenwood Publishing Group.

Syamsuddin, A. R. (2020) 'Pembuktian Penyalahgunaan Wewenang Dalam Perkara Tindak Pidana Korupsi Pengadaan Barang dan Jasa', Jambura Law Review, 2(2), pp. 161-181. doi: $10.33756 /$ jlr.v2i2.5942.

Tarhan, S. (2018) 'Turkish Secondary Education Students' Perceptions of Justice and Their Experiences of Unjustice', Journal of Education and Learning, 7(2), p. 247. doi: $10.5539 /$ jel.v7n2p247.

Yanda, D. P. (2018) 'Teks Cerita Si Palalok Sebagai Upaya Pemahaman Nilai-Nilai Kehidupan Melalui Metode Literasi Kritis', Bahastra, 38(1), p. 20. doi: 10.26555/bahastra.v38i1.7998. 